\title{
The Ukraine-Based Employers' Awareness of Dual Studies and Willingness to Engage into the Implementation of Education Innovations
}

\author{
http://doi.org/10.21272/bel.4(3).137-144.2020
}

Olena Buchynska, ORCID: https://orcid.org/0000-0003-2991-2110

$\mathrm{PhD}$ in Economics, Associate Professor, Department of Marketing, Kyiv National Economic University, Ukraine

Olena Davlikanova, ORCID: https://orcid.org/0000-0001-8536-3959

Doctoral Candidate, Project Coordinator, Friedrich Ebert Foundation, Office in Ukraine, Kyiv, Ukraine

Helmut Hofstetter, ORCID: https://orcid.org/0000-0002-7263-2520

Professor, Berlin School of Economics \& Law, Berlin, Germany

Iryna Lylyk, ORCID: https://orcid.org/0000-0003-4748-5407

$\mathrm{PhD}$ in Economics, Associate Professor, President of the Ukrainian Marketing Association, Kyiv, Ukraine

\begin{abstract}
The article presents the results of the survey conducted among the Ukraine-based companies in 2020 as of their awareness and attitudes to the dual studies (DS) and openness to cooperation with higher educational establishments. After six years of activities aimed at establishing grounds for the adaptation of the German dual studies models conducted by the Friedrich-Ebert-Stiftung Office in Ukraine (FES-Ukraine) and its partners, including the Ukrainian Marketing Association (UMA), the Ministry of Education and Science of Ukraine (MES) launched a pilot project on dual studies introduction in 2019 (MES Order \#1296). The first year of the experiment covered partnerships of 44 pre-tertiary and tertiary educational establishments with around 100 Ukraine-based companies. In 2020 FES-Ukraine and UMA in cooperation with the Federation of Metallurgy Workers of Ukraine and HR Volunteer Association, have conducted a study among two groups of employers - those that represent partner-companies engaged in the project and those not involved into the experiment on the DS introduction. This article presents the results of the survey among the second group of employers. It allowed not only to study the level of awareness and attitude of the employers to DS but to inform companies not involved into the experiment about the initiative that might result in amendments to the list of the experiment participants in the Order \#1296 and enlargement of the number of dual studies cooperation cases. The authors' questionnaire survey was carried out from May to September 2020 in the format of phoneinterviews. The respondents included 400 Ukraine-based companies representing big, medium and small businesses from all the Ukrainian regions apart from the occupied territories of Crimea, Donetsk and Luhansk oblasts. The findings show that a wide information campaign is needed to raise the employers' awareness of the opportunities provided by the dual studies, which is being successfully adapted and integrated in the Ukrainian tertiary education. Therefore, the data obtained is a source of information for recommendations to the stakeholders (especially, policy-makers, employers and their associations) aimed at promoting further cooperation of higher educational establishments and Ukraine-based companies, thus, establishing framework for investments into the training of workforce as a prerequisite of companies' compatibility and the growth of not only individual economic actors, but the national economy. The FES-Ukraine funded the research.
\end{abstract}

Keywords: Dual Higher Education, Dual Form of Education, Dual Studies, Dual Study Models, Employers, Higher Educational Institutions, Ministry of Education and Science of Ukraine, Pilot Project, Students, Tertiary Education.

JEL Classification: I20, I23.

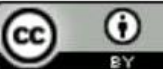

Cite as: Buchynska, O., Davlikanova, O., Hofstetter, H., Lylyk, L. (2020). The Ukraine-Based Employers' Awareness of Dual Studies and Willingness to Engage into the Implementation of Education Innovations. Business Ethics and Leadership, 4(3), 137-144. http://doi.org/10.21272/bel.4(3).137-144.2020.

(C) The Authors, 2020. This article is published with open access at Sumy State University. 


\section{Introduction}

The unprecedented technological development and the shift to the knowledge-based economy lead to rising of employers' expectations as of knowledge and skills of the labor force. The competitiveness of a company directly depends on the efficiency of its employers' work, which, to a great extent, relies on the training received. Thus, for decades stakeholders, including policy-makers, discuss the ways of closing the gap between the expectations from and results of the education received in educational establishments (Andrews G., 2012; Rowe L., 2019). The need to review the approaches applied, especially in tertiary education, is underlined by policy-makers and employers urging for modernization of the content of education, emphasizing the importance of the practical application of theoretical knowledge and the role of the private sector in the eradication of skill gap (UNESCO, 2016; WEF, 2017; EU, 2020).

The concept of dual studies ("Duales Studium") refers to the very specific approach, which foresees the combination of studies in a higher educational establishment (HEE) and a company. It was developed in the Federal Republic of Germany in 1974 when the dual training concept was implemented as a pilot project with 50 companies located around Stuttgart and Mannheim. 164 students combined studies at Vocational Academies (Berufsakademien) and the companies' premises. Later on, the first dual tertiary educational establishment - the Cooperative State University of Baden-Württemberg ("Duale Hochschule BadenWürttemberg") - was created, laying grounds for the dual studies models to develop and spread all over Germany and abroad (Nolting T., 2013; Dimako A., 2018).

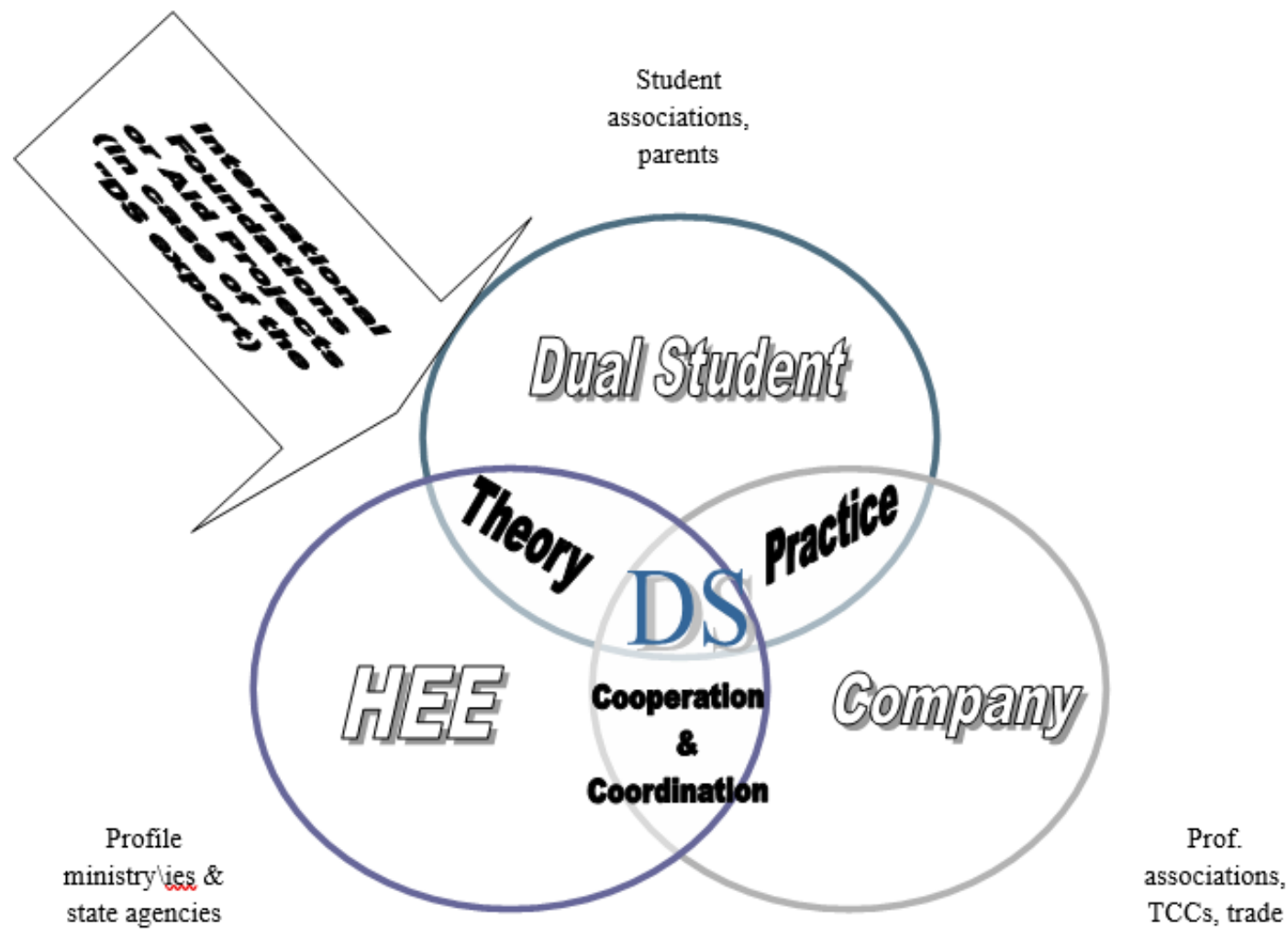

Figure 1. DS Concept and Stakeholders

Source: Developed by Olena Davlikanova based on BiBB materials

Dual studies are getting more and more attention in the last two decades not only in Germany, but many countries around the globe concerned with their economic development, especially about the changes in the labor market demands caused by the fourth industrial revolution and globalization, and eager to import dual studies (Graf L. et al., 2014). The import of dual studies requires considering many factors (Maschke K., 2015). Among them, there are the peculiarities of the education system, traditions of employers' involvement in youth training, and, most importantly, companies' willingness to participate in dual studies and invest in students. These were the employers who had founded the first dual tertiary educational establishment; it is their needs that boosted the establishment of professional academies and universities of applied science in Germany that offer a variety of dual programs. Today, 1700 dual programs are accredited, and 108.000 students have chosen dual studies (Hofmann S., et al., 2020). 


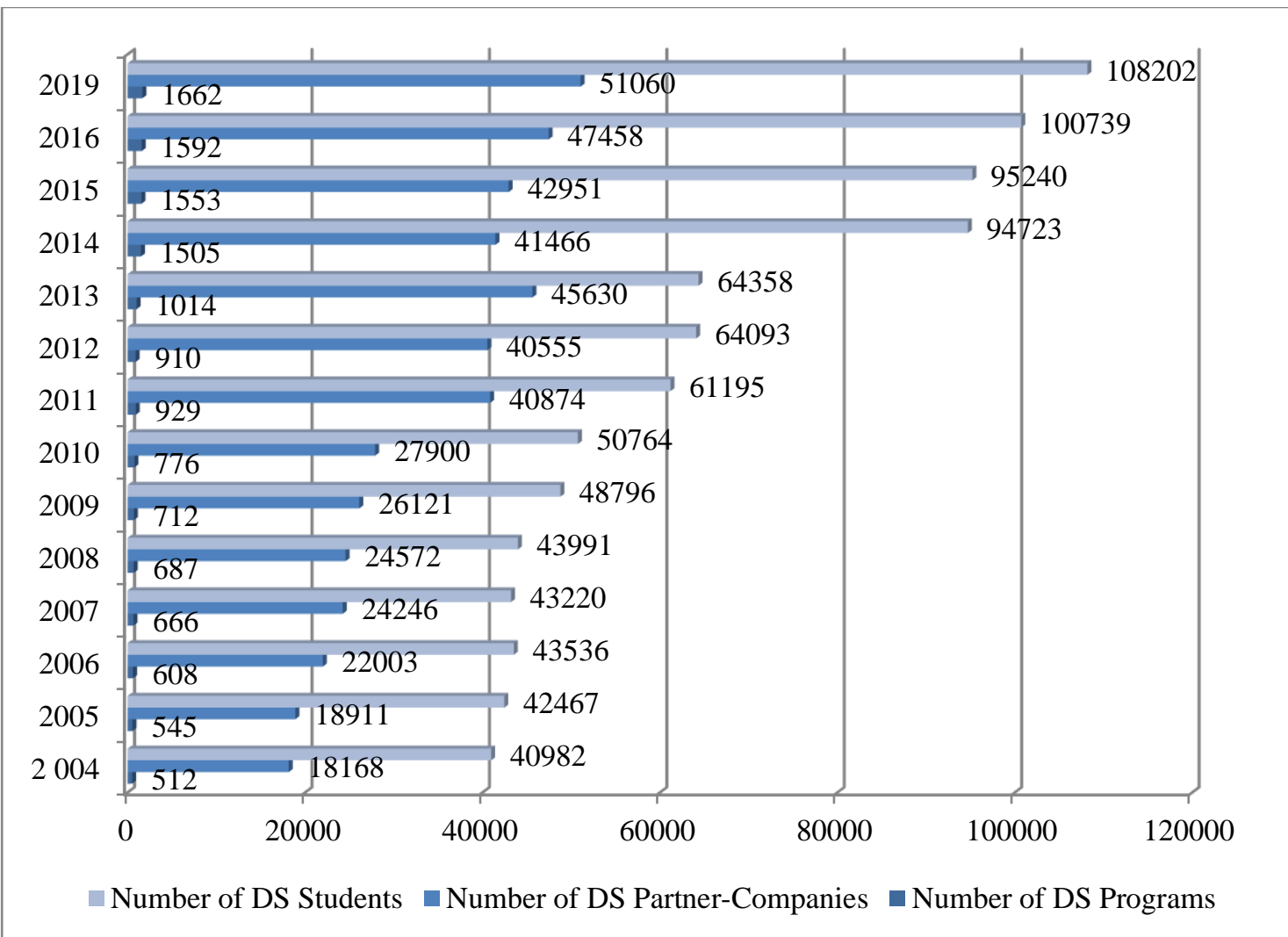

Figure 2. Dynamics of DS Development in Germany (2004-2019)

Source: Developed by Olena Davlikanova based on BiBB materials (BiBB, 2020)

The Friedrich-Ebert-Stiftung Office in Ukraine launched a project aimed at importing and adapting duals studies to the national context back in 2013 to assist the education reform in Ukraine and its economic development. As a result, the normative basis was elaborated, including the adoption of the Concept of Dual Education $\backslash$ Studies and amendments to the Laws "On Education" and "On Higher Education". All factors created the background to launch the national level experiment by the Ministry of Education and Science of Ukraine in 2019. The investigation is expected to last till 2023 and is widely supported by the FES-Ukraine and its partners. The participants are listed in the MES Order \#1296, which includes 44 pre-tertiary and tertiary education establishments and almost a hundred companies operating on the country's territory. The participants' list will be reviewed and amended according to the results of each year of the experiment and include more HEEs and companies volunteering. Thus, it is essential to measure the level of awareness of dual studies among employers not involved in the experiment. It would allow establishing milestones for the future information campaign based on the outcomes of the experiment and involve more participants to enlarge the number of DS introduction cases in Ukraine.

The article includes four parts. The first part - literature review - presents an overview of earlier studies and reports of state institutions dedicated to the dual studies and the role of the employers in its promotion and implementation; the second part - methodology and research methods - outlines methods of the authors' questionnaire survey conducted in 2020; the third part - results - summarizes the main findings of the authors' questionnaire survey; the fourth part - conclusions - presents implications for an ongoing experiment conducted by the Ministry of Education and Science of Ukraine and recommendations for its further development in Ukraine.

\section{Literature Review}

Rapid technological change requires work-ready graduates with complex qualifications (Rainie L., 2017). Massive shifts in the skills demanded on the labor market of the fast-changing world of work put the adequacy of current education systems under question (WEF, 2020). Governments are urged to look for solutions focusing on cooperation with the private sector, while companies are launching their own programs for uplreskilling of the workforce and training of apprentices WEF, 2017). Germany is internationally known for its dual VET and dual studies, which foresee the cooperation of an educational establishment and a company as two places of study. However, the concept of duality is different in the framework of vocational education and training and tertiary education due to the difference in the objectives of these two education levels. The 
overall idea of VET or professional education principles integration into tertiary education is relatively new for Germany and the dual study concept is still being discussed (BiBB, 2017). Though German VET system has traditionally been considered a major factor of the smooth youth transition from school to the labor market, an increasing rate of young people preferring tertiary education to VET boosts the development of the dual study programs (duale Studiengänge) (Ertl H., 2020). Combining academic studies and work experience dual study programs are seen as a way of training highly qualified and real-world-oriented workforce (Graf, 2014). A few countries are experimenting with the adaptation of German dual VET and dual studies to national contexts (Powell J. et al., 2014; Giannelli N., et al., 2017). Ukraine also recognizes the need in adoption of new solutions to overcome the skill gap and is ready to experiment with dual studies (Cabinet of Ministers of Ukraine, 2018).

\section{Methodology and Research Methods}

The questionnaire was based on the preliminary results of the research on the first year of the experiment on dual studies introduction in Ukraine (Davlikanova O., et. al., 2020). It consists of the three groups of questions the first, on the size, location and other information needed to build a company profile; the second, on the previous experience of the Ukraine-based companies' cooperation with higher educational establishments or organization of their own in-company training programs; the third, on their awareness and understanding of dual studies concept and readiness to launch collaboration with HEEs in the framework of DS. All the questions were multiple-choice with the possibility to provide additional details by the respondent or open ones. The method applied was CATI (Computer Assisted Telephone Interviewing), which was carried out in July 2020 by the New Image Marketing Group thanks to the funding provided by the FES-Ukraine. Random sampling was applied for extraction of the respondents' contacts from the open data base YouControl. The authors analyzed the data gathers later. The hypothesis tested is as follows: as of 2020 Ukraine-based companies are poorly aware of the dual studies and are unwilling to invest in students' education due to the lack of state financial motivation mechanisms or guarantees of investment return after student's graduation.

\section{Results}

The number of companies contacted is 3808 , out of which 1958 could not have been reached. Among 1450 companies refusing to participate in the survey, 572 named total unawareness of dual studies as a reason for non-participation. Thus, the response rate is 0,48 ; the valid response coefficient is 0,21 .

Table 1. Sample Design

\begin{tabular}{|c|c|c|c|}
\hline $\begin{array}{c}\text { Number of Companies } \\
\text { Contacted }\end{array}$ & $\begin{array}{c}\text { Number of Companies } \\
\text { Reached }\end{array}$ & $\begin{array}{c}\text { Number of Companies that Refused } \\
\text { to Participate in the Survey }\end{array}$ & $\begin{array}{c}\text { Number of Companies } \\
\text { Covered by the Survey }\end{array}$ \\
\hline 3808 & 1850 & 1450 & 400 \\
\hline
\end{tabular}

Source: Developed by the authors based on the data provided by the New Image Marketing Group

As for the company-portraits, the respondents represent micro, small, middle and big businesses from all the regions of Ukraine: $24,8 \%$ of the companies that took part in the study have their headquarters or main production sights in Kyiv and Kyiv oblast, 12,3\% - in Dnipro oblast, 6,8\% - Lviv oblast, 6,3\% - Poltava oblast, $4,8 \%$ - in Kharkiv and Odesa oblast each, 0,5-3\% - for each of the other regions.

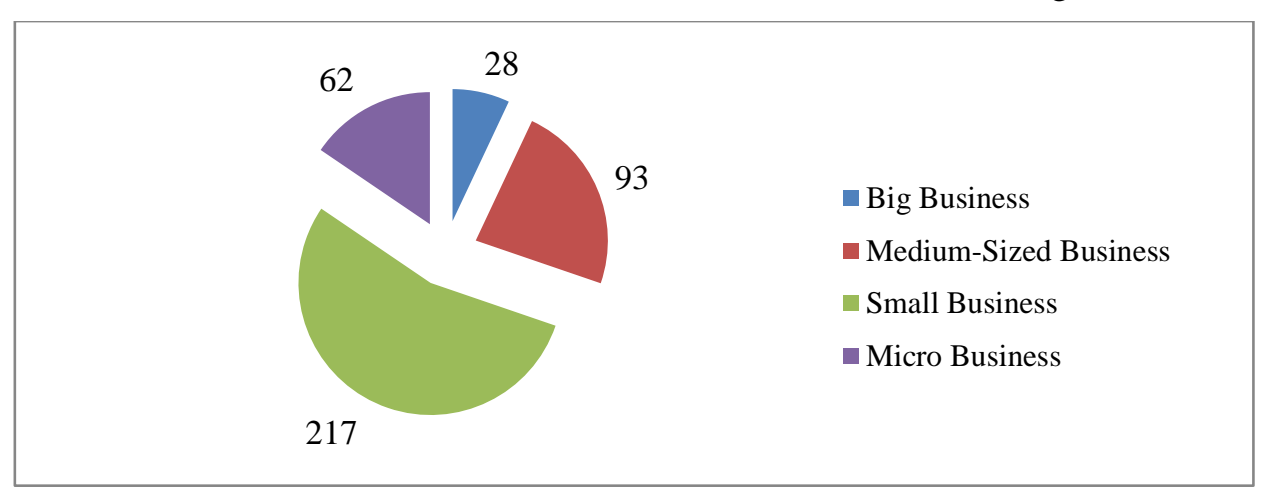

Figure 3. Distribution of the Respondents Companies by Size

Source: Developed by the authors based on the data provided by the New Image Marketing Group

Only $9 \%$ of the respondents are the members of the Federation of Employers of Ukraine and $15 \%$ are the members of other professional associations. 


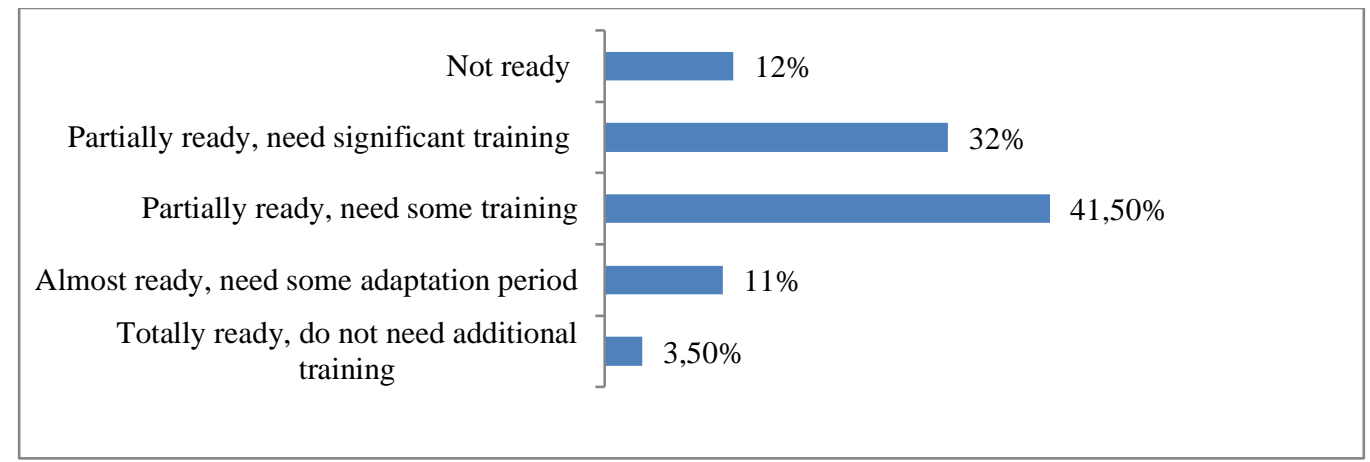

Figure 4. Assessment of the Readiness of HEE Graduates to Work in a Company

Source: Developed by the authors based on the data provided by the New Image Marketing Group

Nevertheless, 75,5\% of the respondent does not conduct any independent activities on the training of HEE students, $0,3 \%$ have created company-based academies, $0,5 \%$ have established hubs, $1,8 \%$ have special labs, $1,8 \%$ have established corporate "universities" (company-based training courses), 20,1\% reported about other initiatives like webinars, internships or competitions of young talents. Only 102 companies out of those interviewed have an experience of cooperation with HEEs, which includes the provision of company's facilities for students' practice, participation in professional orientation activities or examination commissions, sending employers to lecture in HEEs etc. 26 of them mentioned that faced difficulties establishing such cooperation.

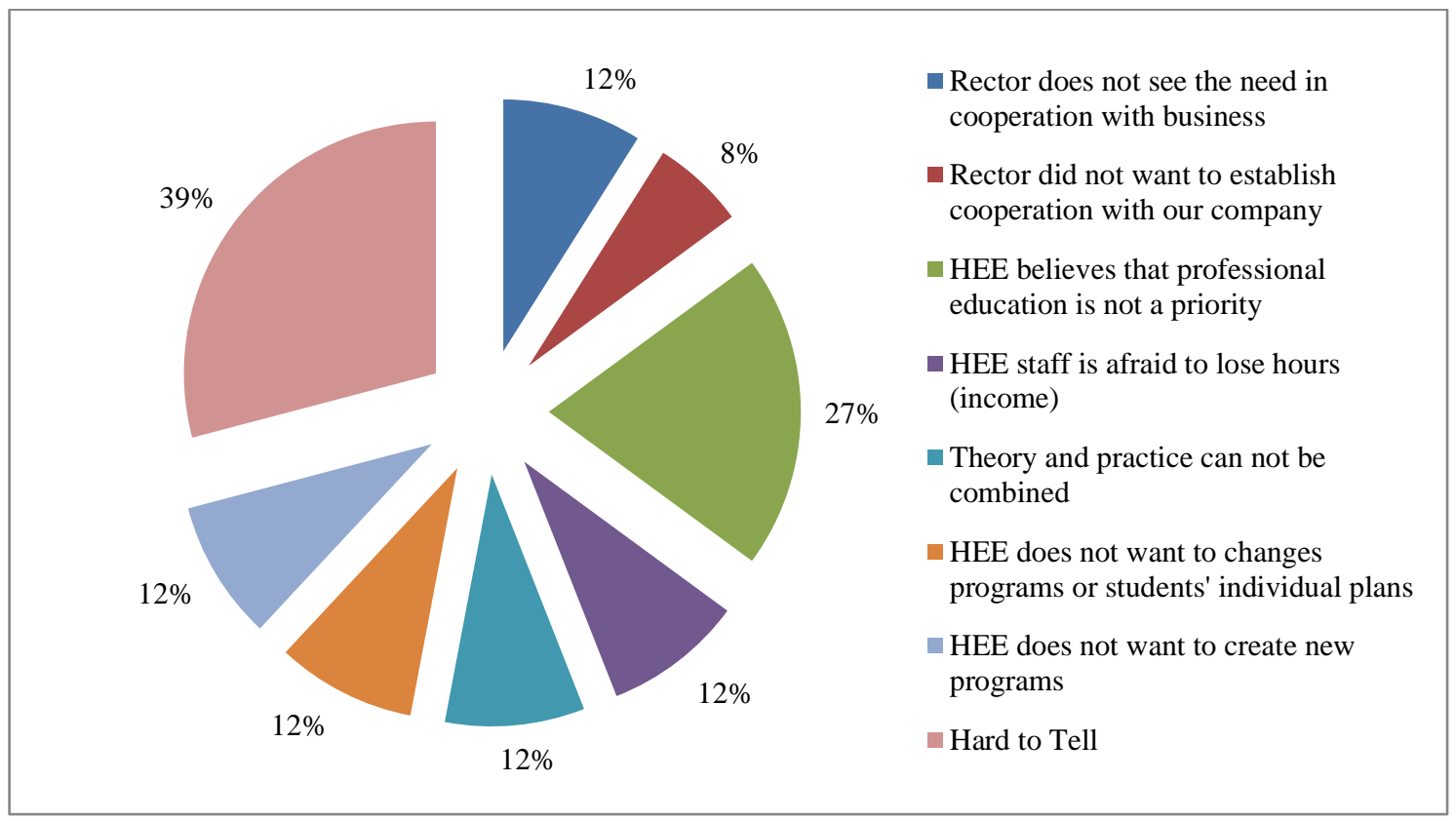

Figure 5. Challenges Faced by Employers Preventing Establishment of Cooperation with HEEs

Source: Developed by the authors based on the data provided by the New Image Marketing Group (the sum of response shares > $100 \%$ as it was a multiple-choice question)

Only 124 companies among the respondents have heard of the dual form of education. The option "other sources" $(27 \%)$ include self-information, participation in the international projects, information from the family members, from the Ukrainian Marketing Association. 


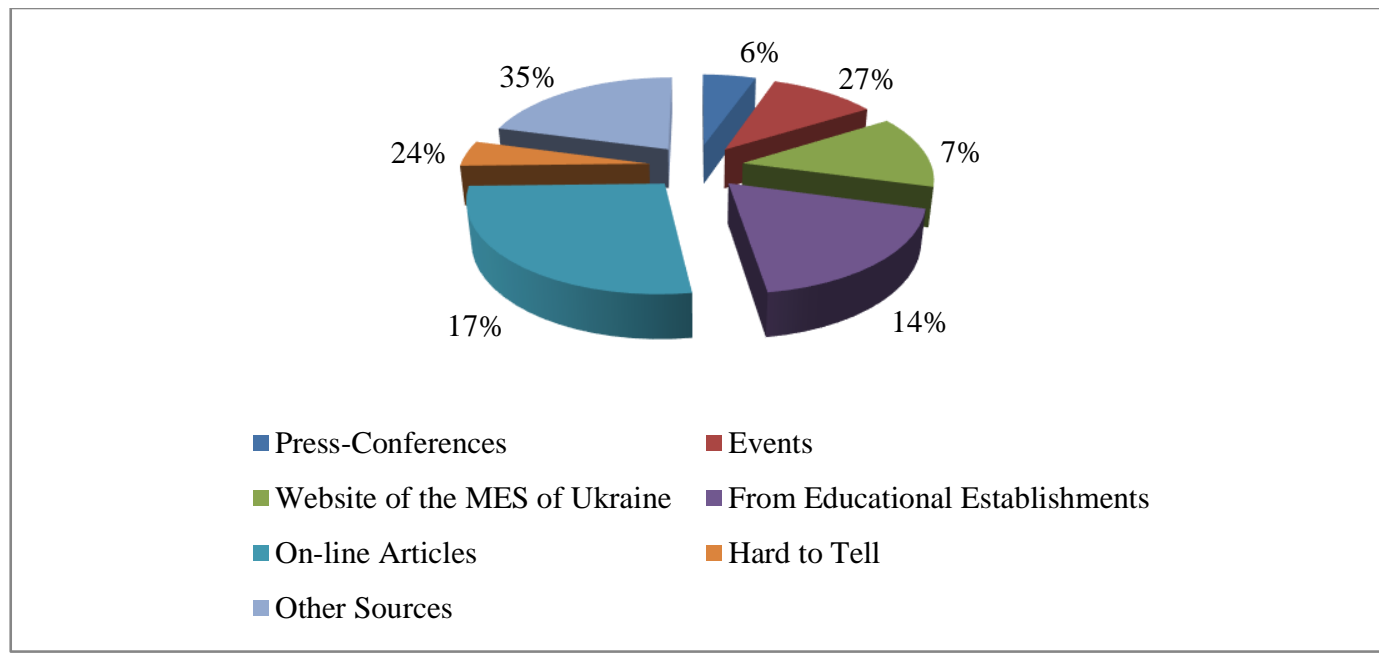

Figure 6. Sources of the Information on DS used by Employers

Source: Developed by the authors based on the data provided by the New Image Marketing Group

The interviewers explained the essence of DS for those unaware to receive informed answers afterwards. $80 \%$ of all the respondents see certain benefits in DS like:

$>$ a possibility to get a specialist right after his her graduation;

$>$ training of a specialist acknowledged with peculiarities of company's work processes and corporate culture;

$>$ shortening of the adaptation period of the newly employed;

$>$ possibility to modernize education programs;

$>$ possibility to get additional labor force for less costs;

$>$ social effect and improving company's image.

Still, as of $202046,7 \%$ of the respondents are not ready to become partners of HEEs for DS introduction, while only $27,5 \%$ are ready to do so.

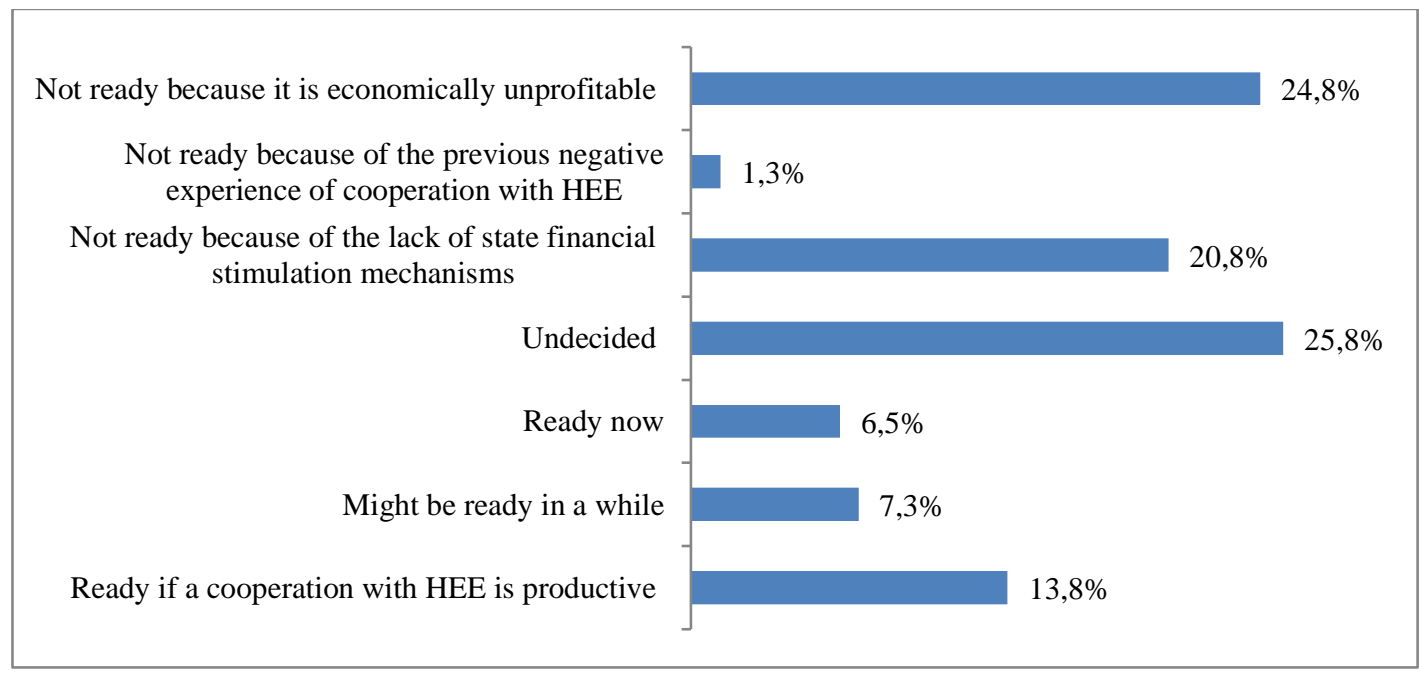

Figure 7. Readiness of Companies to Get Involved in Dual Studies

Source: Developed by the authors based on the data provided by the New Image Marketing Group

$6,25 \%$ of the respondents see no obstacles that might hinder the DS introduction. Others have listed several challenges, among them:

$>$ unstable situation in the country;

$>$ low quality of education provided by HEEs;

$>$ lack of guarantees that a student remains to work in a company or even the country;

$>$ unwillingness of employers to participate in time and costs-consuming initiatives.

Nevertheless, $43 \%$ of the respondents claimed that if they decide to introduce DS, they might agree to cover the education fees and $44,5 \%$ might invest in the training of masters facilitating students during the in-company training periods. Overall, $76,5 \%$ of the companies participating in the survey believe state-private partnership 
in education is important. $69,5 \%$ said that they see possibilities of cooperation between employers that would enable establishment of educational establishments that have only dual programs (analogues of Berufsakademien or the Cooperative State University of Baden-Württemberg). The most demanded majors according to the 327 respondents are in the following fields of knowledge: agronomy, IT, automation and engineering, management, marketing, transport, chemistry, and bioengineering.

\section{Conclusions}

The results have shown that Ukraine-based companies are poorly aware of the dual studies and the possibility of joining the Ministry of Education and Science of Ukraine experiment or launching similar partnerships with HEEs independently. As of employers' willingness to invest into in-company training of students, the rate of almost $46,7 \%$ is relatively high and it becomes even higher with a share of those undecided, who will not be in favor of participation in DS implementation. As employers' active participation and investments are key to the success of dual education, it is essential to conduct an in-depth study of the factors that undermine their readiness to get involved in this initiative. At this stage of the experiment, employers often raise their concerns regarding the lack of state financial motivation mechanisms and norms that oblige a student to work for a company after graduation for several years. The first concern regarding the development and introduction of any state financial motivation mechanisms might not be resolved for decades due to the poor state of the Ukrainian economy caused by many factors, including the war and occupation of industrial territories, intense labor migration and recent COVID-19 quarantine. There are no funds available for the provision of state support to companies investing into company-based training of students in dual education. Moreover, such mechanisms may be misused, among other ways, for tax-evasion. The experience of Germany clearly demonstrates that dual education is highly profitable for both companies and national economy without any additional state financial support. Besides, studies of most of Ukrainian students participating in the experiment are already covered from the state budget.

The second concern regarding no return on investments due to the lack of norms obliging students to continue working for the company after graduation should be studied more carefully. For starters, already during the work-based training the return on investments may reach $70 \%$ (Pfeifer H., et al., 2020). The results of the first year of the experiment have demonstrated that if companies create favorable environment, students stay after graduation. Still, big business representatives mention that no matter how favorable conditions are, the overall infrastructure of Ukrainian especially in medium and small cities is one factor of labor force immigration along with unstable political and economic situation, low salary level in comparison to the neighboring countries etc.

Though, the factor that puts the implementation of dual studies currently at risk is the COVID-19 quarantine. Not only the pandemic has hit businesses hard and lead to cuts of both staff and expenditures, but the homeoffice trend will also continue to spread even after the pandemic is over due to technological development and changes of the essence of labor. If, with some effort, HEEs will be able to organize quality on-line education covering the DS theory component, it is impossible to ensure the DS work-based training component in such conditions. Nevertheless, an information campaign should be developed to present employers with all the benefits of dual studies in current conditions and enlarge the experiment participants' list. It will allow gathering of the domestic experience of DS introduction, finish the normative framework development and seed the tradition of close and efficient cooperation between HEEs and employers.

Author Contribution. Conceptualization, Olena Davlikanova; data curation, Iryna Lylyk; formal analysis, Olena Buchynska; funding acquisition, Iryna Lylyk; investigation, Olena Buchynska, Iryna Lylyk; methodology, Olena Davlikanova; project administration, Olena Davlikanova; resources, Olena Davlikanova; software, Olena Buchynska, Iryna Lylyk; supervision, Olena Davlikanova; validation, Olena Davlikanova; visualization, Olena Davlikanova; writing - original draft, Olena Davlikanova; writing - review \& editing, Helmut Hofstetter.

Funding. The study has been conducted thanks to the support of the Friedrich Ebert Foundation Office in Ukraine and was funded by the grant from the Ministry of Education and Science of Ukraine "Reforming the lifelong learning system in Ukraine for the prevention of the labor emigration: a cooperation model of institutional partnership” (№ 0120U102001).

\section{References}

1. Andrews, G., Russell, M. (2012). Employability skills development: strategy, evaluation and impact. Higher Education. Skills and Work-Based Learning, 2(1), 33-44. https://doi.org/10.1108/20423891211197721. 
2. Bundesinstitut für Berufsbildung (2017). Empfehlung des Hauptausschusses des Bundesinstituts für Berufsbildung. Positionspapier der BIBB-Hauptausschuss AG zum dualen Studium [Recommendation of the Central Committee of the Federal Institute for Professional Education. Position paper on the Dual Study]. Available at: https://www.bibb.de/dokumente/pdf/HA169-Akkreditierung.pdf.

3. Bundesinstitut für Berufsbildung (2020). Duales Studium in Zahlen 2019 [Dual studies in Numbers 2019]. Available at: https://www.bibb.de/dokumente/pdf/06072020 AiZ dualesStudium-2019.pdf.

4. Cabinet of Ministers of Ukraine (2018). Concept of Specialists' Training under the Dual Form of Education $\backslash$ Studies. Available at: https://zakon.rada.gov.ua/laws/show/660-2018-\%D1\%80\#Text.

5. Davlikanova, O., Ischenko, T., Chaikovska, A. (2020). Analytical report on the results of the first year of the experiment on the dual studies introduction in the pre-tertiary and tertiary educational establishments. - FES-Ukraine. Available at: http://library.fes.de/pdf-files/bueros/ukraine/16469.pdf.

6. Dimako, A. (2018). Dual studies: a slightly different training-on-the-job. Available at: https://newinbw.de/dual-studies-training-on-job/.

7. Ertl, H. (2020). Dual study programmes in Germany: blurring the boundaries between higher education and vocational training? Available at: https://doi.org/10.1080/03054985.2019.1687438.

8. Giannelli, N., Sergi, V. (2017). Employability as a policy goal of the dual training system school-work of internship in Italian high schools, with a look at the German model. Available at: http://www.econ.uniurb.it/RePEc/urb/wpaper/WP 17 02.pdf.

9. Graf, L., Powell, J., Fortwengel, J., Bernhard, N. (2014). Dual Study Programmes in Global Context: Internationalisation in Germany and Transfer to Brazil, France, Qatar, Mexico and the US/Duale Studiengänge im globalen Kontext: Internationalisierung in Deutschland und Transfer nach Brasilien, Frankreich, Katar, Mexiko und in die USA. Available at: https://www.researchgate.net/publication/271842872_Dual_Study_Programmes_in_Global_Context_Inte rnationalisation_in_Germany_and_Transfer_to_Brazil_France_Qatar_Mexico_and_the_US_Duale_Studi engange im globalen Kontext Internationalisierung in Deutschlan.

10.Graf, L. (2014). Growing in a Niche Dual Study Programs Contribute to Change in Germany's Higher Education. Available at: https://orbilu.uni.lu/bitstream/10993/17869/1/Graf2014_DualStudyProgramsGrowingInANiche.pdf.

11.Hofmann, S., Hemkes, B., Leo-Joyce, S., König, M., Kutzner, P. (2020). AusbildungPlus in Zahlen. Duales Studium 2019. Trends und Analysen [EducationPlus in Numbers. Dual studies 2019. Trends and Analyses]. BiBB. Available at: https://www.bibb.de/dokumente/pdf/06072020 AiZ dualesStudium-2019.pdf.

12.Maschke, K. (2015). Das duale Studium als Exportmodell [Dual studies as an Export Model]. DAAD. Available at: studien/final blickpunkt duales studium.pdf.

13.Nolting, T., Beedgen, R. (2013). Rethinking the relation between higher education and employment - The dual study system of the Baden-Wuerttemberg Cooperative State University as a new way of integrating theory and practice. Available at: http://wwww.pef.unilj.si/fileadmin/Datoteke/Mednarodna/conference/wher/after/nolting-proceedings.pdf.

14.Pfeifer, H., Wenzelmann, F. (2020). Kosten und Nutzen der betrieblichen Ausbildung 2017/18 [Costs and benefits of the in-Company Training 2017]. BIBB. Available at: https://www.bibb.de/tools/dapro/data/documents/pdf/eb 21316.pdf.

15.Powell, J., Fortwengel, J. (2014). Made in Germany - Produced in America? How Dual Vocational Training Programs Can Help Close the Skills Gap in the United States. AICGS Issue Brief, 47. Available at: http://hdl.handle.net/10993/17092.

16.Rainie, L., Anderson, J. (2017). The Future of Jobs and Jobs Training. Available at: https://www.pewresearch.org/internet/2017/05/03/the-future-of-jobs-and-jobs-training/.

17.Rowe, L. (2019). Educating for the modern world: a report review. Journal of Work-Applied Management, 11(1), 5-16. https://doi.org/10.1108/JWAM-06-2019-0014.

18.UNESCO (2016). Incheon Declaration and SDG4 - Education 2030 Framework for Action. Available at: https://unesdoc.unesco.org/ark:/48223/pf0000245656.

19.World Economic Forum (2017). Accelerating Workforce Reskilling for the Fourth Industrial Revolution. An Agenda for Leaders to Shape the Future of Education, Gender and Work. Available at: http://www3.weforum.org/docs/WEF_EGW_White_Paper_Reskilling.pdf.

20.World Economic Forum (2020). Schools of the Future Defining New Models of Education for the Fourth Industrial Revolution. Available at: https://www.weforum.org/reports/schools-of-the-future-defining-newmodels-of-education-for-the-fourth-industrial-revolution. 